\title{
PEDESTRIAN BRIDGES AND PASSAGES IN TERMS OF SPACE DESIGN
}

\author{
Deniz Demirarslan \\ Asst. Prof. Dr., Kocaeli University, Turkey, demirarslandeniz@gmail.com
}

\begin{abstract}
Pedestrian bridges are constructed in various structures and by using various materials in order to ensure safe passage of pedestrians in various situations such as vehicle traffic, animal traffic and natural formations in or out of the city centres. There are bridge or passage designs allowing passage for autos and pedestrians, bicycles and trains as well as bridges used by pedestrians only. We can observe the construction of pedestrian bridges in various civilizations and eras throughout the history. In 19th century, together with the industrial revolution and the invention of steam train, pedestrian bridges were constructed over the railways and after invention of automobile in 20th century and due to the changes and developments in sea, lake and river vehicles, requirement for bridges around highways, sea transportation routes and railways aroused. These bridges sometimes converted into spaces while being monumental accessories of the cities ensuring the formation of cultural and historical identity in settlements.

In this study, the aim is to handle the bridges, which are urban accessory elements, by a scientific research so as to let it constitute a written source for the other future studies to be made about this issue. Under the scope of the study, the historical course related with the design of pedestrian bridges and samples was examined and then classifications were made according to their area of usage, type of usage, material and structure. Finally the spatial loop of pedestrian bridges and today's design measures were examined.
\end{abstract}

Keywords: Pedestrian bridge, footbridge, bridge, design.

\section{INTRODUCTION}

Today, the need for pedestrian bridges has increased within the bridge structures defined as the wooden, concrete or iron structure which links the two sides divided by any obstacle or lets the traffic stream to pass over without interrupting any other traffic stream (Url-1). This definition remains incapable for defining the pedestrian bridges defined as a bridge which is constructed for the access of pedestrians by Turkish Language Society (Url-1).

The pedestrian bridges are the bridges having different structures and constructed by using various materials in order to let the people to walk across the street safely in various cases such as vehicle traffic, animal traffic, natural formations, etc. in and outside the centres of population. There are also bridge or 
passage designs which allow for the access of pedestrians and vehicles such as automobile, bicycle, train, etc. as well as the bridges which are only used by pedestrians.

The pedestrian bridges are an access structure which links two different areas in aesthetic way as a supplementary aspect of landscape and urban design. In most developed countries, the subject is taken into hand from the point of that the pedestrian bridges are designed as a work of art and a statue of city as well as their functionality. In the developing countries, the pedestrian bridges have been gained importance as the structures through which the people may access the trade centres where they may fulfil the health services, education opportunities and needs especially in the rural areas. It is possible to observe that especially the suspension bridge systems are more applied in the rural areas due to the easiness of material supply, easy installation, low labour force and cheapness. The pedestrian bridges are called with different names depending on aspects such as their relation with the ground of bridges and their usage: footbridge, underbridge, skyway, etc. These bridges and passages have sometimes made contribution to the cultural and historical identity formation in the settlements: The bridges located on the channels of Netherlands, Mostar Bridge, Venice bridges, etc. In this paper, the pedestrian bridges and passages which conform to the definition of bridge and act as footbridge will be reviewed.

\section{THE PEDESTRIAN BRIDGES WITHIN THE HISTORICAL PROCESS}

Along with that the pedestrian bridges are perceived as the simple structures, they are necessary and significant for a safe life and safe transportation in the settlement areas and their surrounding in terms of their function. These structures that the people, especially in the centres of population, have to use and see every day are started to be designed by accepting them as aesthetic items of cities by the designers in due course. Since the early ages, the people have constructed wooden bridges for passing over the river and adverse ground conditions. The first bridges were probably constructed by extending wood blocks or putting big stones successively in order to cross over streams. Another method was the bridges which were constructed with the boats and rafts connected in succession. The oldest document concerning to the bridges was document in which the bridge on the Euphrates River in Babel in 8th century B.C is mentioned by Greek historian Herodotus. The findings concerning to the first wooden bridge constructed by using a simple construction technique goes back to 1500 s B.C. The oldest wooden bridge findings were found in the western of Seedamm city on Zurich Lake in Switzerland. With the help of boat a bridge constructed by King Darius in 512 B.C, the Persian armies invaded the South-eastern Europe by passing over Istanbul Strait. Also, the King Kserkses (Xerxes) constructed two adjoining boat bridges in $1.4 \mathrm{~km}$ length consisting of 674 boats in the Dardanelles (519-485 B.C). In addition, a bridge at Eleutherna, in Crete, constructed in the $4^{\text {th }} \mathrm{C}$. B.C just before the vault was introduced in ancient Greece (URL-2, URL-3, and URL- 4).

The Hittites and Urartians conducted public improvement works in Anatolia and the bridges were significant designs among these activities. The Kız Köprüsü (the Maiden Bridge) in Muş which was constructed by Urartians and the bridge in Boğazköy which was constructed by Hittites (it is the first known bridge in the world) are the works which has survived until today. The Clandras Bridge which comes through the Phrygians is among the rare bridges which have survived until today (Çeçen, 2014, p. 252).

The Roman civilization was an advanced civilization in terms of the bridge construction. Another significant example of wooden pedestrian bridges belonging to Roman era was found in Switzerland. This bridge belongs to 2nd century in B.C and the width of this bridge is 6 meters (Jurecka, 1979, p.35). In the cities belonging to Roman civilization, the horse carts had led to accidents in the city by causing a dense and complicated vehicular traffic. Therefore, the secure access of pedestrian had been provided by linking the buildings with the bridges among the high and multi-storey blocks named as "insula". Also, the Roman legionnaires constructed the floating bridges in order to cross over the areas such as river, lakes, etc. The Bridge of Pons Sublicius constructed by the Romans on Tibet River in 621 B.C (150 meters in length) is completely wooden. The bridge which was 420 meters in length and which was completed in 10 days by the command of Julius Caesar on Rhine River in 50 B.C is also wooden. Another technique which was used in the construction of bridge by Roman was the moon stone bridges. The methods used by the Romans, had been used by the Europeans in the bridge construction for hundreds of years (Ulrich, 2007, p. 78). The Buddhist priest, Fa-Hsien mentioned a rope bridge in $92 \mathrm{~m}$ length which was constructed in India in 412 B.C. In the construction of this kind of bridges, the ropes knitted with the thick creeper and bamboo fibers in the forests. China has a long tradition in bridge building. Early Chinese bridges included stone and wooden bridges and rope bridges as well. In addition, Chinese built big bridges of wooden construction, and later stone bridges, and the oldest surviving stone bridge in China is the Zhaozhou Bridge built around 605 AD during the Sui Dynasty (URL-3, URL-4).

The mobile bridges were constructed in the Medieval in order to be able to enter the chateaus enclosed with the ditches (URL-4). It is seen that a wooden bridge was constructed by Austria Duke IV. Rudolf in 1358 and 
1360 and these bridges were brought into service after being reconstructed in 2001 (URL-5). The oldest one among the wooden bridges constructed as covered is the Kopellbrücke Bridge (1333) (in 204 m length). This bridge is a covered passage and it is attractive in terms of its decoration equipped with its indoor images (Charles, 2016:36). It is seen that the clergymen took charge in the construction of bridges in the Medieval. In France, a group of priests founded the sect named "freres du pont" with the aim of designing and constructing solid bridges. The most significant work of this sect is the Pont d'avignon Bridge on the Rhone River. In the same way, a priest named Peter from Colechurch in England constructed the first stone bridge on Thames River (Lay, 1992, p. 265-266).

In the Renaissance period, the bridges especially in Italy are attractive. The bridges of Ponte Vecchio and Venezia Rialto are the significant bridges in this period (Ryall, 2003, p. 7).

If we look at Turkish- Islamic civilisations, The Artuquids, Seljukians and Ottomans are the significant states which constructed bridges in Anatolia. The Malabadi Bridge constructed by the Artuquids (1147) has been the subject of various masterpieces and songs (Günel, 2010: 134). The bridges are among the most significant works of classical era Ottoman architecture. The bridges carry a big significance especially among the works of Sinan the Architect. The Mostar Bridge (1566) which is the work of Hayrettin the Architect who was the student of Sinan the Architect is also a significant pedestrian bridge and today, it has become the symbol of Bosnia Herzegovina. The longest historical stone bridge in the world, Uzunköprü, is located in Edirne. Uzunköprü has 1392 Meters in length and 174 belts.

Until the late 17th century, the bridge design was mostly made by the architects in Europe. The bridge construction had started to be taken into hand by the engineers along with the unity of bridge and highway engineers which was founded by French military engineers in 1718. The first iron bridges were constructed on Severn River, England in 1779 and a steel iron was constructed on Mississippi River in 1874 (URL-6). The Shahara Bridge in Yemen is a famous classical stone bridge which was constructed in order to be used in the war against Ottoman soldiers in 17th century (Mclaughlin, 2007, p. 151).

Two inventions of 19th century, the Portland cement and steel, have led to a revolution in the bridge construction. The significance of Galata Bridge which is located in Istanbul is very big among the bridges of 19th century. The Galata Bridge is a significant brdige which is used by both pedestrians and vehicles. Its history goes back a long way. Various bridges were constructed in the same region along the history before the Galata Bridge. The bridge of Aghios Khalinikos constructed by the Golden Horn by Justinianus in 6th century A.D was constructed between Eyüp and Sütlüce. During the conquest of Istanbul, the Sultan Mehmed Fatih (Mehmed the Conqueror) got a bridge constructed on the Golden Horn. For the bridge consisted of giant barrels between Ayvansaray and Kasımpaşa, Nisancı Mehmed Pasha said that it consisted of the ships anchored side by side and connected to each other with beams. It was planned to construct a bridge on the Golden horn in 1502-1503. Sultan Bayezid II requested Leonardo da Vinci to design a bridge for the Golden Horn. But this bridge was not constructed as the approval of Sultan was not received. The Sultan assigned the same task on Michelangelo but the craftsman refused this offer. The Bridge of "Hayratiye" was constructed between Azapkapı and Unkapanı by Sultan Mahmud II in 19th century. Then, this bridge was also demolished and the second bridge in 1863, the third bridge in 1875 and the fourth bridge in 1912 were constructed in the place of this bridge. In the place of fourth Galata Bridge which burned in 1992, the fifth Galata Bridge was constructed in 1994. Today, it has become traditional icons of Istanbul and new Galata Bridge which links two cultures carries a figurativeness characteristic as it links new Istanbul with old Istanbul (Sezer and Özyalçıner, 2010, p.151).

Today, the construction of pedestrian bridges has continued with various materials and construction techniques. Recently, the world's longest pedestrian bridge has $439 \mathrm{~m}$ height and $1 \mathrm{~km}$ length and it is located in Krasnaya Polyana Valey, Russia (URL-7). The Langkawi Bridge (in $125 \mathrm{~m}$ length) which was constructed in Malaysia in 2005 is a pedestrian bridge allowing for connection between two mountains in 660 $\mathrm{m}$ height (URL-8). The Hudson River Bridge in New York constructed in 2009 (in $2.063 \mathrm{~m}$ length) is a significant tourist attraction which attracts 750.000 tourists in a year. It is possible to see that the pedestrian bridges are designed in very different ways in various regions of world (URL-9).

\section{THE CLASSIFICATION OF PEDESTRIAN BRIDGES}

In accordance with their relations with the ground:

1- Overground bridges/footbridge

2- Underground bridges/underground/tunnel

3- Afloat and/or floating bridges 


\section{4- The Bridges which are positioned between two structures}

In accordance with the materials:

1- Stone bridges

2- Wooden bridges

3- Steel bridges

4- Iron bridges

5- Reinforced concrete bridges

6- Composite bridges

7- Bridges made of knitted materials

In accordance with their functions, the bridges may be classified as follows:

1- The pedestrian bridges which are constructed only for the pedestrians

2- The pedestrian bridges at which the access of pedestrians and unmotorized vehicles are provided

3- The pedestrian bridges at which the access of pedestrians and motorized and unmotorized vehicles are provided

4- The pedestrian bridges to which spatial functions are also loaded along with the pedestrian access (Bridge and store, bridge and restaurant, bridge and dwelling, etc.)

5- The pedestrian bridges where different functions are resolved along with the pedestrian access (Bridge and natural gas line, bridge and railway, etc.)

6- The covered bridges

7- The drawbridges and mobile bridges (The mobile and drawbridges are the bridges which are generally opened by lifting them in order that the vehicles may pass over. Today, the mobile bridges are moon type bridges which are generally suspended to a carrier vehicle. They have mechanical orders allowing for extending the bridge to the opposite shore).

But the most common classification is the classification made in accordance with the carrier system and forms:

1- Suspension bridges

2- Clapper bridges

3- Moon bridges

4- Elbow bridges

5- Zig-zag bridges

6- Stepping stone bridges

7- Truss bridges

8- Lattice truss system bridges (tureng/ lattice truss)

9- The pedestrian bridges in the form of boardwalk

10- The bridges constructed within hybrid system

The suspension bridge is the bridge type which has been most preferred in crossing over the wide clearances. For example; the Arroyo Cangrejillo Pipeline Bridge is a pedestrian bridge constructed with the classical suspension system which links the valleys where the gold and copper mines near Las Estancias, Argentina are located; at the same time, they are used for the transmission of pipeline. Another significant example for these suspension bridges is the Capilano Bridge on Capilano River in Canada (1889). This bridge has $140 \mathrm{~m}$ length and $70 \mathrm{~m}$ height (URL-10).

The clapper bridges are one of the oldest carrier systems. In England, Tarr Steps Bridge was constructed by stacking the big stones consisting of granite and schists (Riley, 2013, p.4). The moon bridges are designed in the way that it will not lead to any strain at any point. Therefore, the concrete is very convenient for the moon bridge design. The elbow bridge consists of two beams each of which is supported from one end. A 
buttress is located at both ends of clearance. The bridge is completed by connecting to two opposite branches. Contrary to the bridges with straight beam supported from both ends, the upper-sections of elbow bridge supported from one end must resist to the strain and its sub-sections should resist to the pressure. The steel bridge which has the longest elbow is the Quebec Bridge which was constructed in Canada in 1918 (URL-11).

The stepping stone bridges are generally constructed in the way that the stones are aligned successively in order that the people may cross over the water easily. Along with that it has simple types historically, there are recently the stepping stone bridges which are specially designed. The zig-zag bridges are seen especially in the landscaping of Japanese and Chinese gardens. As it is believed in the Zen belief that the evil spirits act comfortably on the straight ways, the pedestrian bridges are constructed in the form of zig-zag in the Japanese and Chinese gardens in order to prevent the evil spirits to walk comfortably (Young and Young, 2005, p. 151).

The truss bridges are constructed by using various materials such as wood, reinforced concrete, iron, steel, etc. The lattice truss bridges were first constructed as wooden by Roman. In the Renaissance period, the wooden lattice truss bridges were constructed (Okten,1995, p. 132). It may be arranged as console as well as that it may be in the form of lattice truss arch.

The boardwalk is constructed in order that the pedestrians may walk on the natural formations such as beach, river bank, lake, forest in a more convenient and ergonomic way. One of the most prominent one of these ways is the boardwalk which was constructed in New Jersey, USA in 1870. There are also mixed structured bridges constructed by using aforementioned methods together. For example; the bridle bridge consists of a long straight beam partially supported with steel ropes which are suspended from the tower in an end or towers at both ends. They are designed in the way that there will be many spaces and this space is passed with a simple and straight joisting. The "drawbridges" like famous bridge of London, the Tower Bridge" have elbowed branches or bascules.

\section{THE DESIGN CRITERIA OF PEDESTRIAN BRIDGES}

Today, the minimum criteria which should be conformed in the design of pedestrian bridges have been determined with various standards in developed countries: Austroads 13- 4- 2 in Australia, BS 5400 Part 2 in Britannia, CSA-56-00 Section 4 and OHBDC in Canada, AASHTO in United States of America, Dansk Standard in Denmark, EC1, EC2, EC5 in Europe, Fasicule Special 72-21 in France, DIN 180241, DIN 1072, DIN- Fachbericht 101-102 in Germany and Japanese Footbridge Design Code 1979 in Japan, etc. But these criteria generally have been determined for the pedestrian bridges which are located on the highway.

Among these, the standards of pedestrian bridges in Britannia are one of the standards which have the widest scope. In accordance with these standards, it is recommended that the speed limit should not exceed if there will be vehicular traffic on the pedestrian bridge along with the pedestrians, the distance between two carriers of bridges should be at least 2 meters in the bridges which have been constructed only for the pedestrians, the pedestrian bridge should have the necessary height $(\mathrm{min} .4,5 \mathrm{~m})$ in order that the vehicles may pass over if the pedestrian bridge is located on the highway, the topography should be taken into consideration in the selection of form, structure and position of bridge, any step and ramp should not be used if possible, the ramp should be preferred instead of step, the handicapped should be considered in the design of element such as step, ramp, etc., a separate way should be considered for the pedestrians if there will be vehicular traffic, the connection of pedestrian bridges to other pedestrian ways should be provided easily, the design should be easily perceivable and accessible in the way that it will promote the pedestrians to cross over, the access safety of pedestrians should be provided and they should be in compliance with the places such as city, nature, protected areas, national park, historical environment, etc. It is also stated in the same standards that the width of $30 \mathrm{~cm}$ is required to be calculated for 20 persons per minute in the design of bridges, the width of bridge steps and ramps should be $\min .2 \mathrm{~m}$ and $30 \mathrm{~cm}$ width should be considered for 14 persons per minute at the widths of ramp and steps. In the steps, the number of steps should not be higher than 13, the landings should be left, the step height should be max. $15 \mathrm{~cm}$ and the step width should be $\geq 30 \mathrm{~cm}-\leq 35 \mathrm{~cm}$. The safety rail should be $\min .5 \mathrm{~cm}$ and max. $10 \mathrm{~cm}$. The step safety rail heights should be min. $90 \mathrm{~cm}$ and max. $1 \mathrm{~m}$. The standard dimension of bridge safety rail is $1.15 \mathrm{~m}$; the safety rail may be extended up to $130 \mathrm{~cm}$ in the areas where strong wind blows. If the glass safety rail will be used, the laminated glass should be used. For example; the laminated glass at $51.8 \mathrm{~mm} \times 1800 \mathrm{~mm} \times 900 \mathrm{~mm}$ dimensions was used in the flooring of pedestrian bridge in Madrid Barajan Airport. In accordance with the standards in Spain, the safety rail height should be $\min .75 \mathrm{~cm}$ and max. $95 \mathrm{~cm}$. The internal height of indoor bridges should be $2.30 \mathrm{~m}$ for the pedestrians, $2.40 \mathrm{~m}$ for the bicycles and vary between $2,70-3,70$ for the cavalcades. In the bridges, the drainage system should be considered. The coating materials should be resistant to the atmosphere conditions and non-slippery materials should be used (URL-12, URL-13, URL- 
14). The lighting of sidewalk and steps on the bridge is significant. In the regulation issued by General Directorate of Highways in Turkey, min. height has been determined as $4.80 \mathrm{~m}$ for the footbridges on the highways and there is no further standard.

Another factor which affects the design of pedestrian bridges is the vibration. The vibration depends on the walking way and speed of pedestrian and the speed of vehicle, if any. Therefore, the soldiers cross over the bridges freely in order to decrease the vibration. If a roadway passes under the bridge, the vibration coming from the roadway also affects the pedestrian on the bridge. Another issue which should be paid attention in terms of bridges is that the pedestrians are affected from the environmental noise. Also, the selection of material and structure should be resistant to the physical factors and vibration (URL-15).

It is significant to lighten the sidewalk and steps on the bridge. The lighting elements should be resistant to the corrosion and vandalistic effects. The lighting should be direct lighting down to the ground. In the regulations in Spain, it is recommended to use 10 lux lighting at the starting and ending point of pedestrian bridge ramp and min. 10 lux lighting at CEI and IDEA standards on the bridge. The lightings provide the remote perception of bridge and have visual comfort and aesthetic tasks (Guidelines for the design of footbridges).

Another issue which should be paid attention in the design of pedestrian bridges is that the bridges should conform to the universal design rules. No matter they are constructed on natural formations or roadway, the use of pedestrian bridges by everybody should be provided: The handicapped, old persons, children, pregnant, etc. Therefore, the vertical and horizontal circulation should conform to the universal design rules. Another design criterion which have been recently paid attention is the resistance to the earthquake, hurricane, wind, etc. For example; the Krasnaya Polyana Bridge which was constructed as the world's longest pedestrian bridge in Russia was constructed as resistant to 9-magnitude earthquake.

\section{RESULT}

It is seen that the pedestrian bridges which had been constructed with the functional purposes in past have been recently taking on the task of being symbols of cities and even countries. The pedestrian bridges which have become indispensable aspects of theme parks taking place among the recreation areas of today are the significant structures of design world. As well as that they are engineering works with their various construction methods and material use, the pedestrian bridges are architectural works as they carry the architectural style characteristics of current period. At the same time, some bridges are interior architecture works as they carry the characteristic of being a space and we see some bridges as the urban furniture design. In the recent years, these bridges which have examples constructed in various styles such as modern, futuristic, deconstructivity, ecological, etc. have samples that have been taken into hand with the kitsch approach especially in our country and these bridges threaten the identities of city. Especially, the design criteria of pedestrian bridges which take place on the highways have been identified with the standards in the developed and developing countries; the ergonomics, resistance to the natural conditions and vandalism, vibration, circulation characteristics and conformity to the universal design criteria have become the most significant design criteria in other pedestrian bridge designs.

\section{REFERENCE LIST}

Charles, V. (2016). Bridges. Litres Publishing.

Çeçen, K. (2014). Türk İslam Ansiklopedisi. cilt: 26; sayfa: 253,http://www.islamansiklopedisi.info/dia/pdf/c26/c260155.pdf

Guidelines for the design of footbridges. The International Federation for Structural Concrete, Bulletin no 32.

Günel, G. (2012). Anadolu Selçuklu Dönemi'nde Anadolu'da İpek Yolu - Kervansaraylar - Köprüler. Kebikeç, 29: $133-146$.

Jurecka, Ch. (1979). Historische Entwicklung Fazination der Technick. Wien, Wien-München: Verlag Anton Schroll Co.

Lay, M.G. (1992). Ways of the World. New Jersey: Rutgers University Press.

Mclaughlin, D. (2007). Yemen. Bradt Travel Guides: London.

Okten, A. (1995). Structural Engineering and Industrial Revolution. Ekrem Hakkı Ayvedi Commemorative Book, p. 132, Istanbul: Istanbul Fetih Cemiyeti. 
IJASOS- International E-Journal of Advances in Social Sciences, Vol. III, Issue 7, April 2017

Riley, H. (2013). An Historical and Archeological study of Tarr Steps. Exmoor National Park, AIFA, FSA, Devon.

Ryall, M.J., Parke, G.A.R., Harding, J.E., (2003). Manual of Bridge Engineering. London: Thomas Telford Pub.

Sezer, S., Özyalçıner, A., (2010). Öyküleriyle İstanbul Anıtları. Ankara: Evrensel Basım

Ulrich, R., B. (2007). Roman Woodworking. London: Yale University Press.

Young, D., Young, M. (2015). The Art of the Japanese Garden, Singapore: Tuttle Publishing.

URL-1: www.tdk.gov.tr, accessed date: 27.12.2016

URL-2: http://www.historyofbridges.com/, accessed date: 27.12 .2016

URL-3: http://theconstructor.org/structures/history-of-bridges/5491/, accessed date: 27.12.2016

URL-4:http://www.contre.no/pdf/jenhob_col.pdf, accessed date: 27.12.2016

URL-5: http://www.historyofbridges.com/bridges-history/wooden-bridges/, accessed date: 27.12.2016

URL-6: http://www.eutouring.com/pont_des_arts_history.html, accessed date: 27.12.2016

URL-7: http://www.viralnova.com/terrifying-bridge/, accessed date: 27.12.2016

URL-8: http://adib.typepad.com/blog/files/steel_design_award.pdf, accessed date: 27.12.2016

URL-9: http://nysparks.com/parks/178/details.aspx, accessed date: 27.12.2016

URL-10: https://www.capbridge.com/, accessed date: 27.12.2016

URL-11: http://www.asce.org/project/quebec-bridge/, accessed date: 27.12.2016

URL-12: http://www.tiipublications.ie/library/DN-STR-03005-02.pdf, accessed date: 27.12.2016

URL-13: http://www.stb.rwth-aachen.de/projekte/2007/HIVOSS/docs/Footbridge_Guidelines_EN03.pdf, accessed date: 27.12 .2016

URL-14: http://www.stb.rwth-aachen.de/projekte/2007/HIVOSS/docs/Footbridge_Background_EN02.pdf, accessed date: 27.12 .2016

URL-15: ftp://193.136.28.78/pub/Pessoal/Dec/manuel/CD\%20Workshop_Pedro/IDW01_Heinmeyer.pdf, accessed date: 27.12 .2016 